\title{
Laparoscopic Vs Open Anatrophic Nephrolithotomy Operative Outcomes and Comorbidities
} \author{
Almanzor-González Octavio ${ }^{1}$ \\ ${ }^{1}$ Department of Urology, Hospital civil de guadalajara "Fray Antonio Alcalde" México \\ ${ }^{2}$ Department of Urology, Hospital civil de guadalajara "Fray Antonio Alcalde" México \\ ${ }^{3}$ Department of Urology, Universidad de Sonora, Sonora \\ ${ }^{4}$ Department of Endourology, Hospital Regional de Alta Especialidad del Bajío, Gto \\ ${ }^{5}$ Department of Orthopedic, Hospital Centro Medico de Occidente, Jalisco
}

Gómez-Regalado Francisco ${ }^{2 *}$, Manzo-Pérez Braulio ${ }^{4}$, Jimenéz-Avila José María ${ }^{5}$, Arriaga Aguilar Juan ${ }^{3}$ and

Submission: February 18, 2017; Published: April 11, 2017

*Corresponding author: Gómez-Regalado Francisco, Department of Urology, Hospital civil de guadalajara "Fray Antonio Alcalde" México, Email: f_gore_87@hotmail.com

Abstract

Introduction: Management of staghorn calculi in terms of complete clearance and low morbidity is a technically challenging issue even with open surgery. The aim of the study is to compare laparoscopic surgery as a less invasive procedure than open surgery.

Methods: A control-case study was performed, all patients with staghorn calculi treated by laparoscopic or open anatrophic nephrolithotomy between 2014 and 2015 we included. Age, stone diameter, surgical time, warm ischemia time, blood loss, transfusion, waiting time for surgery, complications, stone-free rate and hospital stay were evaluated. Analysis was carried out in STATCAL Epi info 7.

Results: There were 15 patients that met inclusion criteria, 8 were undergone to laparoscopic and 7 to open surgery. Age range was 42.1 vs 49.5 years, stone size $52.63 \mathrm{~mm}$ vs $44.7 \mathrm{~mm}$, surgical time 127.5 vs $121.4 \mathrm{~min}$, warm ischemia 29.5 vs $33 \mathrm{~min}$. (OR 10, p=>.05), blood loss 218.7 vs $837.1 \mathrm{ml}$, transfusion rates were $0 \%$ vs. $57 \%$, complications $25 \%$ vs $57.14 \%$ (OR .25, p= >.05) , hospitalization days 3.5 vs 6.14 days (OR 6, $\mathrm{p}=>.05$ ) and stone-free rate was $75 \%$ vs $57 \%$ (OR $2.25, \mathrm{p}=<.05)$ respectively.

Conclusion: Our results seems to show that laparoscopic nephrolithotomy have a higher stone free rate, less complication, warm ischemia rate and a short hospitalization stay compared with open surgery, although it is necessary a mayor sample of patients and prospective studies that corroborates this results.

Keywords: Anatrophic; Nephrolithotomy; Lithiasis; Calculi

Abbreviations: PCNL: Percutaneous Nephrolithotomy; SWL: Shock Wave Lithotripsy; AN: Anatrophic Nephrolithotomy; LAN: Laparoscopic Anatrophic Nephrolithotomy; OAN: Open Anatrophic Nephrolithotomy

\section{Introduction}

Even in this modern era of endourology where we have experienced mayor technological advances and technical improvements, management of staghorn calculi remains a big challenge especially in obtaining a stone-free status with low morbidity. By definition staghorn calculus occupies more than $80 \%$ of the collecting system or the renal pelvis and more than one single calyx [1]. It is not uncommon that a stone free status for a staghorn calculus is not achieved after several sessions with endourological techniques and even after an open, laparoscopic or robotic surgery.

In past decades percutaneous nephrolithotomy (PCNL) and shock wave lithotripsy (SWL) have revolutionized renal calculi management. It is because of its minimally invasive nature and high effectiveness with less morbidity that they have replaced open surgery for big renal calculi treatment. Nowadays, PCNL it is the first line treatment for renal calculi $>2 \mathrm{~cm}$ and for those in lower renal pole $>10 \mathrm{~mm}$. However, in big renal calculi (staghorn calculi) PCNL could not get a stone free status even with more than one procedure [2]. Stone free rates for anatrophic nephrolithotomy (AN) could not be 
depended on nephrolitometric mesurements like PCNL does and could reach success rates of $75-95 \%$ in a single procedure, this is the reason why in many centers AN continue to be a very attractive therapeutic option in patients with sthaghorn calculi $[3,4]$. Laparoscopic surgery has been used to replicate different open surgeries used for ureteral and renal stones management. Laparoscopic anatrophic nephrolithotomy (LAN) has been described as an effective, safe and reproducible method in experienced centers, however, it presents higher rates of complications compared to PCNL, and higher renal function loss (7-27\%) in the affected kidney but could be less invasive and more effective than open anathrophic nephrolithotomy [4-6].

\section{Material and Methods}

A case-control study was carried out to compare laparoscopic to open nephrolithotomy. With this purpose all patients diagnosed with staghorn calculi that were undergone to laparoscopic or open anatrophic nephrolithotomy (OAN) at "The Antiguo Hospital Civil de Guadalajara", between 2014-2015 were included. Laparoscopic surgeries were performed by the same surgeon and open surgery was performed by 2 different surgeons. All patients were admitted the day before their surgery because of the administrative protocol of our hospital and all the patients received preoperative antibiotic prophylaxis. We performed the statistical analysis in STATCALC of Epi info 7and perform descriptive analyzes taking into account measures of central tendency and dispersion. The inferential analysis was performed using contingency tables $(2 \times 2)$ and $\mathrm{x} 2$ was calculated using the corrected Yates test. We performed the OR test, obtaining its value and as hypothesis test the confidence interval of $95 \%$.

\section{Laparoscopic technique}

After general inhaled anesthesia a double "J" catheter was placed in all cases at the beginning of surgery in lithotomy position and then the patient was positioned in a lateral decubitus position. For left sided surgery we used 4 trocars and for right sided surgeries we added an extra $5 \mathrm{~mm}$ trocar. First we place a $10 \mathrm{~mm}$ trocar for a 30 degrees lens at the level of a imaginary pararectal line $3-4 \mathrm{~cm}$ above the navel, then we place a second $10 \mathrm{~mm}$ trocar at $8-9 \mathrm{~cm}$ right sided of the first trocar, a third $5 \mathrm{~mm}$ trocar is placed $8-9 \mathrm{~cm}$ left sided of the first one trying to making up an imaginary triangle by these first trocars. Finally a fourth trocar is placed on the posterior axillary line as a support for renal retraction and If the procedure is on the right side an additional $5 \mathrm{~mm}$ trocar is placed to retract the liver.

A transperitoneal approach was performed in all patients and the first step once all trocars are placed in their right position it is Told's fascia dissection and colon movilization. Then all anatomical structures such as duodenum or liver (if a right sided surgery), are dissected until renal hilum get adecuately exposed to be clamped. We continue with dissection of anterior and posterior perirenal fat until renal capsule get completely discovered and having adequate exposure of both sides of the kidney and renal hilum. Renal artery (only) get clamped with a bulldog clamp and the pneumoperitoneum pressure it is increased until reach $20 \mathrm{mmHg}$ to reduce risk of bleeding, a pneumoperitoneum pressure of $14 \mathrm{mmHg}$ the set for the rest of the surgery (Figure 1). A laparoscopic scalpel (blade number 11) to perform the incision in renal parenchyma. Incision was performed $(3-4 \mathrm{~cm})$ trying to identify the avascular Brödel line in the kidney, a difficult issue because it is not a straight line and it has irregularities in its path [7]. Once the collector system is opened and the stone is exposed (Figure 2), an alice clamp is introduced to release the stone, always trying to remove it in one piece (Figure 3). Collector system is then explored with the 30 degree lens for residual stone. As a final step prior to removal of the bulldog clamp, the renal parenchyma is closed with 2-0 polyglactin with a hem-o-lock reinforcement (Figure 4). We remove bulldog clamp and hemostasia is controlled but if bleeding is observed, «X» suture points were placed as much as necessary, thereafter gelfoam (Figure 5) were placed at the site of the renal parenchyma incision. It is very important to keep warm ischemia time to a maximum of 30 minutes because prolonged ischemia causes a greater renal damage [7]. As a last step we introduced the stones in a bag (Figure 6). Then JacksonPratt type drainage was left in place.

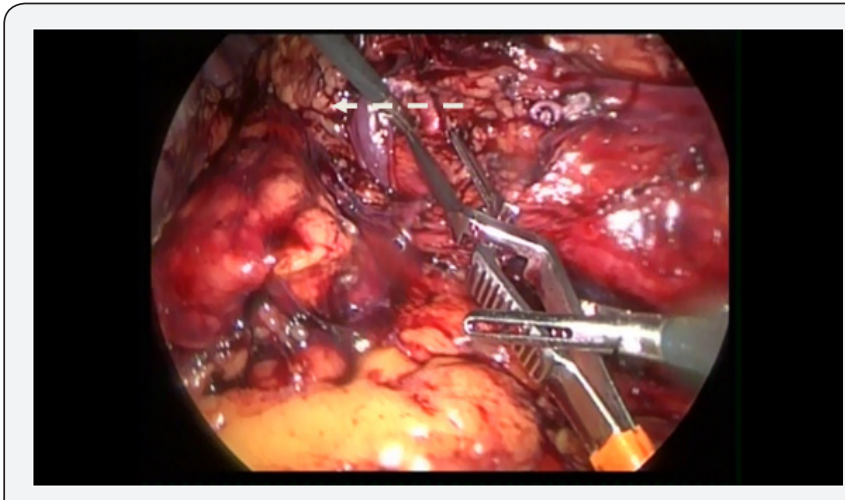

Figure 1: Renal artery (marked with an arrow) get clamped with a bulldog clamp.

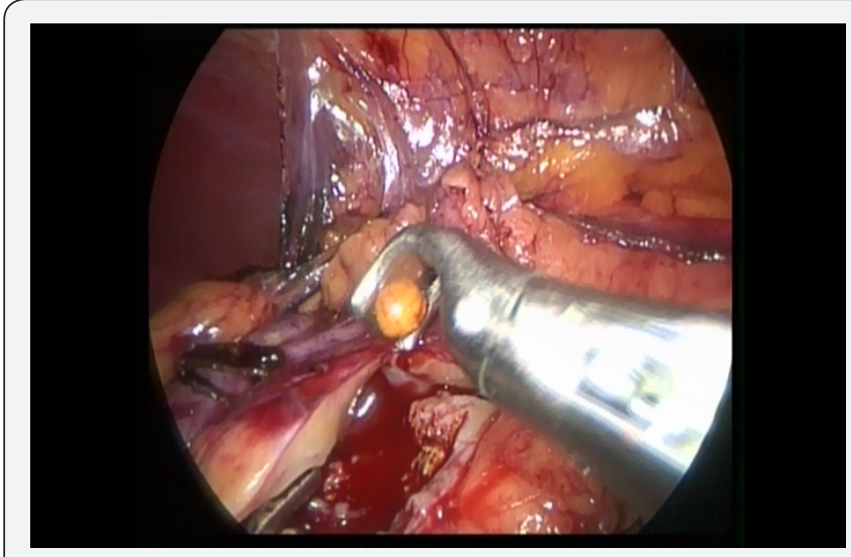

Figure 2: Stone exposition. 


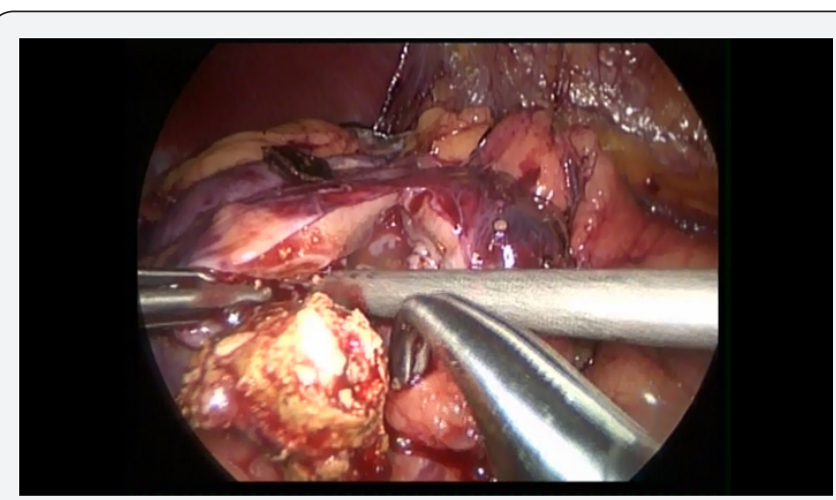

Figure 3: Alice clamp is introduced to release the Stone.

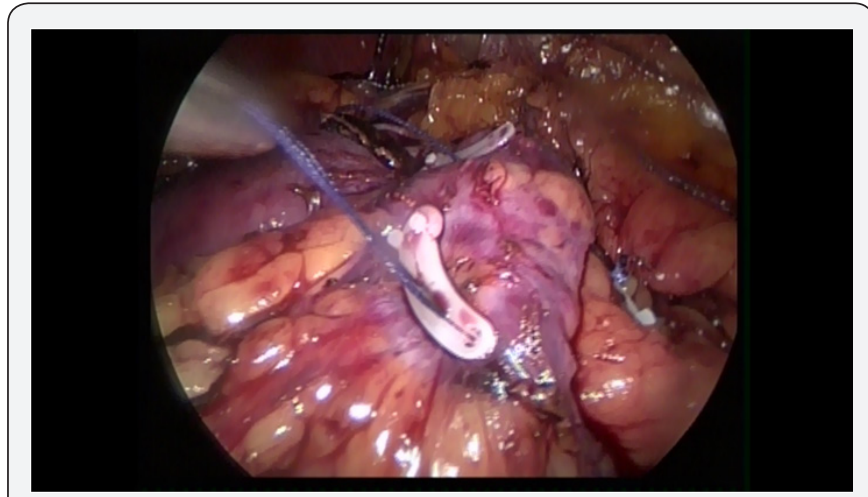

Figure 4: Renal parenchyma is closed with 2-0 polyglactin with a hem-o-lock reinforcement.

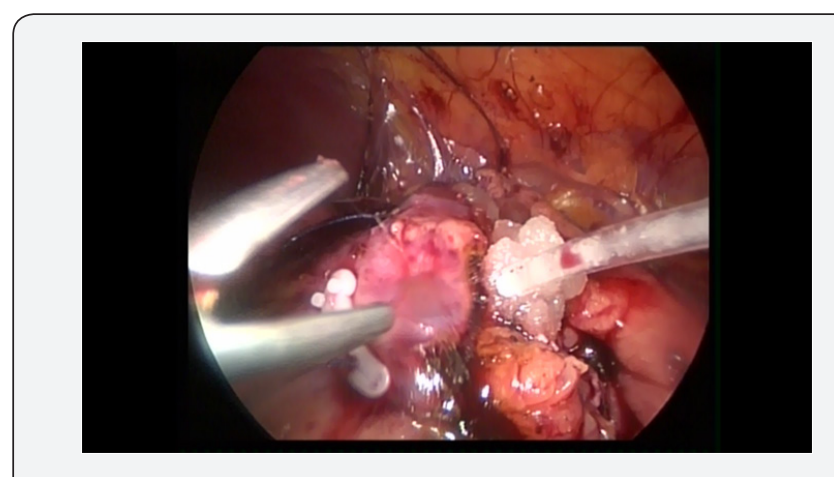

Figure 5: Gelfoam placed at the site of the renal parenchyma incision.

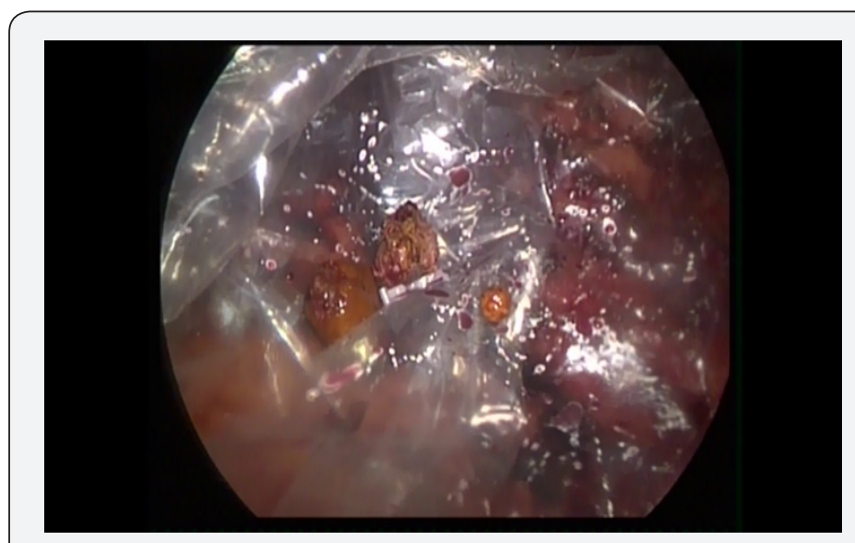

Figure 6: Introducing the stones in a bag.

\section{Results}

Table 1: Patient Characterisics.

\begin{tabular}{|c|c|c|c|c|c|c|c|c|c|c|c|c|c|c|c|c|}
\hline \multicolumn{17}{|c|}{ Patient Charecteristics } \\
\hline \#Patient & 1 & 2 & 3 & 4 & 5 & 6 & 7 & 8 & 9 & 10 & 11 & 12 & 13 & 14 & 15 & Mean \\
\hline Surgery & LAP & LAP & LAP & LAP & LAP & LAP & LAP & LAP & $\mathrm{OP}$ & $\mathrm{OP}$ & $\mathrm{OP}$ & $\mathrm{OP}$ & $\mathrm{OP}$ & $\mathrm{OP}$ & $\mathrm{OP}$ & NV \\
\hline Age & 33 & 31 & 40 & 47 & 38 & 46 & 44 & 58 & 77 & 42 & 44 & 42 & 40 & 60 & 42 & 45.60 \\
\hline $\begin{array}{c}\text { Stone Diameter } \\
(\mathrm{mm})\end{array}$ & 42 & 50 & 65 & 46 & 45 & 48 & 60 & 65 & 33 & 50 & 50 & 55 & 50 & 40 & 35 & 48.93 \\
\hline Side & LE & LE & RI & LE & RI & LE & LE & RI & LE & LE & RI & LE & LE & RI & LE & NV \\
\hline Surgery Time & 110 & 110 & 150 & 90 & 110 & 110 & 110 & 230 & 120 & 120 & 120 & 120 & 80 & 170 & 120 & 124.67 \\
\hline WIT & 25 & 14 & 32 & 30 & 25 & 30 & 35 & 45 & 35 & 28 & 35 & 35 & 30 & 35 & NA & 31.00 \\
\hline Blood Loss & 150 & 100 & 550 & 200 & 150 & 300 & 150 & 150 & 710 & 200 & 700 & 2200 & 100 & 150 & 1800 & 507.33 \\
\hline Transfusión & NO & NO & NO & NO & NO & NO & NO & NO & SI & NO & SI & SI & NO & NO & SI & NV \\
\hline SWT & 4 & 4 & 6 & 6 & 6 & 12 & 12 & 4 & 10 & 12 & 12 & 7 & 12 & 18 & 6 & 8.73 \\
\hline Complications & NO & NO & NO & NO & $\mathrm{SI}^{*}$ & NO & NO & SI*** & SI Ç & NO & NO & $\mathrm{SI}^{* * * *}$ & NO & SI \& & $\mathrm{SI} * *$ & NV \\
\hline Stone Free Rate & SI & SI & SI & SI & SI & NO & SI & NV & SI & SI & NO & SI & NO & SI & NA & $\mathrm{NV}$ \\
\hline HSD & 4 & 3 & 3 & 3 & 4 & 4 & 4 & 3 & 5 & 5 & 6 & 4 & 3 & 5 & 15 & 4.73 \\
\hline
\end{tabular}


LAP: Laparoscopic; OP: Open; SWT: Surgery Waiting Time; HSD: Hospital Stay Days; WIT: Warm, Ischemia Time

*Late Nephrectomy 10 days after Surgery

${ }^{* *}$ Nephrectomy for Incontrollable Bleeding

*** Nephrectomy for Prolonged Ischemia

****Vascular Injury (Vena Cava)

Ç: Splenic Injury

\&: Ureter Injury

A total of 15 patients were undergone to anatrophic nephrolitotomy, $8(53.3 \%)$ patients were submitted to laparoscopic and 7 (46.6\%) to open suegery. No one patient that was undergone to laparoscopic surgery required conversion to open surgery (Table 1). Mean age in LAN was 42.1 years and OAN was 49.5 years and stone diameter was $52.6 \mathrm{~mm}$ vs $44.7 \mathrm{~mm}$ respectively. In the laparoscopic group 5 stones $(62.5 \%)$ were found in left topography and 3 stones $(37.5 \%)$ in right topography, mean while in the open group 5 stones $(71.4 \%)$ in left topography and 2 stones $(28.5 \%)$ in right side. Surgical time in LAN was 127.5 minutes and 121.4 minutes for OAN. The warm ischemia time in the LAN group was 29.5 minutes, it was performed a nephrectomy in a patient due to

Table 2: Laparoscopic Vs Open. prolonged ischemia, in the OAN group an average of 33 minutes (OR 10, $p=>0.05$ ) was obtained, a patient was excluded from this parameter because a vascular injury at the moment of placing bulldog clamp, we decided to perform nephrectomy in this patient. The blood loss in the LAN group was $218.7 \mathrm{ml}$ and in the OAN group $837.14 \mathrm{ml}$, with a percentage of transfusion for the LAN group of $0 \%$ and $57 \%$ respectively. The complications were classified as immediate complications: trans operative nephrectomy which represented $12.5 \%$ LAN group (one patient) and OAN group $14.2 \%$ (one patient), in the LAN group no splenic lesion was reported in OAN group one patient that represents $14.2 \%$, ureteral lesion $0 \%$ in the LAN group and $14.2 \%$ OAN group (one patient), vascular injury (cava vein) $0 \%$ in LAN group and $14.2 \%$ OAN group. Late complications were present only in one patient in the LAN group, who presented at the emergency room with hematuria 9 days postoperatively, which did not yield to medical treatment, and performed emergence nephrectomy (OR .25, $p=>.05$ ) . The free stone rate, which was demonstrated with a simple tomography before hospital discharge, was $75 \%$ for LAN group was and $42.8 \%$ for OAN group (OR 2.25, $\mathrm{p}=<0.05$ ). Hospital stay were lower for the LAN group, mean of 3.5 days, and for the OAN group, 6.1 days (OR 6, p=>0.05). (Table $2 \& 3$ ).

\begin{tabular}{|c|c|c|}
\hline \multicolumn{3}{|c|}{ Laparoscopic Vs Open } \\
\hline & Laparoscopic & Open \\
\hline \#Patients & 8 & 7 \\
\hline Age & 42.13 & 49.5 \\
\hline Stone Diameter (mm) & 52.63 & 44.7 \\
\hline Left Side & 5 & 5 \\
\hline Right Side & 3 & 2 \\
\hline Surgery Time & 127.5 & 121.4 \\
\hline WIT & 29.5 & $33^{*}$ \\
\hline Blood Loss & 218.75 & 837.14 \\
\hline Transfusion & 0 & $4(57 \%)$ \\
\hline SWT & 6.75 & 11 \\
\hline Immedia Complications & $1(12.5 \%)$ & $4(57 \%)$ \\
\hline Late Complications & $1(12.5 \%)$ & 0 \\
\hline Free Stone Rate & $75 \%(6)$ & $57 \%(4)$ \\
\hline $\mathrm{DDH}$ & 3.5 & 6.14 \\
\hline
\end{tabular}

SWT: Surgery Waiting Time

HSD: Hospital Stay Days

*We excluded a patient who presented vascular lesión, after placement of bulldog clamp 
Table 3: Analysis of anatomic nephrolithotomy variables.

\begin{tabular}{|c|c|c|c|c|c|c|c|}
\hline \multicolumn{8}{|c|}{ Analysis of Anatomic Nephrolithotomy Variables } \\
\hline Variables & \multicolumn{2}{|c|}{ SI } & \multicolumn{2}{|c|}{ NO } & \multirow[t]{2}{*}{ OR } & \multirow[t]{2}{*}{ IC $95 \%$} & \multirow[t]{2}{*}{$\mathrm{P}$} \\
\hline Complications & $\mathrm{Fr}$ & $\%$ & $\mathrm{Fr}$ & $\%$ & & & \\
\hline Laparoscopic & 2 & 25 & 6 & 75 & 0.25 & $0.02-2.23$ & $>.05$ \\
\hline \multirow[t]{2}{*}{ Open } & 4 & 57.14 & 3 & 42.8 & 1 & & \\
\hline & \multicolumn{2}{|c|}{ SI } & \multicolumn{2}{|c|}{ NO } & OR & IC $95 \%$ & $\mathrm{P}$ \\
\hline $\begin{array}{c}\text { Free Stone } \\
\text { Rate }\end{array}$ & LAP & $\%$ & $\operatorname{Fr}$ & $\%$ & & & \\
\hline Laparoscopic & 6 & 75 & 2 & 25 & 2.25 & $0.25-20.13$ & $<.05$ \\
\hline \multirow[t]{2}{*}{ Open } & 4 & 57.14 & 3 & 42.86 & 1 & & \\
\hline & \multicolumn{2}{|c|}{ TIC $(\leq 30)$} & \multicolumn{2}{|c|}{ TIC9>30) } & OR & IC 95\% & $\mathrm{P}$ \\
\hline WIT & $\mathrm{Fr}$ & $\%$ & $\mathrm{Fr}$ & $\%$ & & & \\
\hline Laparoscopic & 5 & 62.5 & 3 & 37.5 & 10 & $0.77-128.78$ & $>.05$ \\
\hline \multirow[t]{2}{*}{ Open } & 1 & 14.29 & 6 & 85.71 & 1 & & \\
\hline & \multicolumn{2}{|c|}{$\mathrm{DDH}(\leq 3)$} & \multicolumn{2}{|c|}{ DDH $(>3)$} & OR & IC 95\% & $\mathrm{P}$ \\
\hline HSD & $\mathrm{Fr}$ & $\%$ & $\mathrm{Fr}$ & $\%$ & & & \\
\hline Laparoscopic & 4 & 50 & 4 & 50 & 6 & $0.47-75.34$ & $>0.5$ \\
\hline Open & 1 & $14.29 \%$ & 6 & $85.71 \%$ & 1 & & \\
\hline
\end{tabular}

WIT: Warm Ischemia Time

HSD: Hospital Stay Days

\section{Discussion}

Nowadays the treatment of choice for renal stones $>2 \mathrm{~cm}$ is PCNL $[9,10]$. In 1968 smith and Boyce first described anatrophic nephrolithotomy but recently with the technology and urologic advances this technique had lost popularity. AN could be considered in some situations like these: failed endourological procedures, anatomical variations of the collecting system that difficult the percutaneous nephrolithotomy, neccessity of anatomical reconstruction of an uretero-pelvic junction structure, surgeon experience and trainin and skeletal abnormalities
$[11,12]$. Reports has been shown that open surgery presents higher comorbidities compared to PCNL $[13,14]$.

Melissourgos et al. [15] reported for open surgery a mean operation time of 180 minutes, $500 \mathrm{ml}$ blood loss and transfusion rate of $8.3 \%$ ( 2 patients), mean hospital stay 8.2 days, they made to 9 patients DMSA to determinate pre and post operative renal function and they observe that they loss only a $4 \%$ of function, stone free rate $83.3 \%$ [15]. We made a comparison between this results (Table 4 ).

Table 4: Comparison Open Surgery Resutls.

Comparison Open Surgery Results

\begin{tabular}{|c|c|c|c|c|c|c|}
\hline & N. Patients & OPT & Blood loss & Transfusion & HOSD & FSR \\
\hline Meliss Orgos & 24 & 180 & $500 \mathrm{ml}$ & $0 \%$ & 8.2 \\
\hline Our Study & 7 & 121.4 & $837.14 \mathrm{ml}$ & $57 \%$ & 6.14 & $57 \%$ \\
\hline
\end{tabular}

OPT: Operation Time; HOSD: Hosptial Stay Days; FSR: Free Stone Rate 
OPT: Operation Time; HOSD: Hosptial Stay Days; FSR: Free Stone Rate In the laparoscopic technique there's a few information published probably because the high grade complexity or a predominant percutaneous treatment. Zhou et al. has one of the biggest case series with 11 patients, the operative time range in all the studies we compared was 139-192 minutes, the ischemia range was $20.8-32.8$, the stone diameter range $67.3-52 \mathrm{~mm}$, and the complications they report urinary leakage and vascular fistula [16-18] (Table 5).

Table 5: Perioperative results of the series of cases of laparoscopic anatomic nephrolithotomy.

\begin{tabular}{|c|c|c|c|c|c|c|}
\hline \multicolumn{7}{|c|}{ Perioperative results of the series of cases of laparoscopic anatomic nephrolithotomy } \\
\hline Study & \#Patients & Surgery Time & WIT & STDI & SFR & Complications \\
\hline Simforoosh (2008) [5] & 5 & 170 & 32 & 53 & $60 \%$ & Niguna \\
\hline Zhou (2011) [17] & 11 & 139 & 31 & 52 & $90.90 \%$ & Urinary leakage (3) \\
\hline Gieldmann (2012) [18] & 8 & 142.5 & 20.8 & 53 & $62.50 \%$ & Vascular Fistula (1) \\
\hline Amin Sharifi (2013) [4] & 10 & 192 & 32.8 & 67.3 & $80 \%$ & Esplenic Injury \\
\hline Nuestro estudio & 8 & 127.5 & 29.5 & 52.6 & $85.70 \%$ & $\begin{array}{c}\text { emergence nehprectomy y 1 } \\
\text { late nephrectomy }\end{array}$ \\
\hline
\end{tabular}

STDI: Stone Diameter; SFR: Stone Free Rate; WIT: Warm Ischemia Time

Based on our analysis the stone free rate in a single staged procedure has better results with laparoscopic surgery than to open surgery.

\section{Conclusion}

Laparoscopic nephrolithotomy seems to have a higher stone free rate, less complication, warm ischemia time and hospital stay compared to open surgery. LAN could be a therapeutic option for renal staghorn calculi with high stone free rates in a single procedure in selected patients that are no candidates for PCNL, in centers with experience in laparoscopic surgery or those that PCNL is not available. However larger caser series and prospective studies are needed to compare all therapeutic options including PCNL and confirm these results.

\section{References}

1. Aminsharifi A, Hadian P, Boveiri K (2013) Laparoscopic Anatrophic Nephrolithotomy for Management of Complete Staghorn Renal Stone: Clinical Efficacy and Intermediate-Term Functional Outcome. J Endourol 2795): 573-578.

2. Mishra S, Sabnis RB, Desai M (2012) Staghorn morphometry: A new tool for clinical classification and prediction model for percutaneous nephrolithotomy monotherapy. J Endourol 26(1): 6-14.

3. Assimos DG (2001) Anatrophic nephrolithotomy. Urology 57(1): 161165 .

4. Aminsharifi A, Irani D, Masoumi M, Goshtasbi B, Aminsharifi A, et al. (2016) The management of large staghorn renal stones by percutaneous versus laparoscopic versus open nephrolithotomy: a comparative analysis of clinical efficacy and functional outcome. Urolithiasis 44(6): 551-557.

5. Simforoosh S, Radfar MH, Nouralizadeh A, Tabibi A, Basiri A, et al. (2013) Laparoscopic Anatrophic Nephrolithotomy for Management of Staghorn Renal Calculi. J Laparoendosc Adv Surg Tech 23 (4): 306-310.

6. Adamy A, Favaretto RL, Nogueira L, Savage C, Russo P, et al. (2010) Recovery of renal function after open and laparoscopic partial nephrectomy. Eur Urol 58(4): 596-601.
7. Bhupendra P, Urmila D (2013) Re: Laparoscopic Anatrophic Nephrolithotomy: Developments of the Technique in the Era of Minimally Invasive Surgery. J Endourol 27(1): 108-108.

8. Kaouk JH, Gill IS, Desai MM, Banks KL, Raja SS, et al. (2003) Laparoscopic anatrophic nephrolitotomy: Feasibility study in a chronic porcine model. J Urol 169(2): 691-696.

9. Tu“rk C, Petr`ı'k A, Sarica K, Seitz C, Skolarikos A, et al. (2016) EAU guidelines on interventional treatment for urolithiasis. Eur Urol 69(3): 475-482.

10. Skenazy J, Ercole B, Lee C (2005) Nephrolithiasis: "Scope," Shock or Scalpel? J Endourol 19(1): 45-49.

11. Swearingen R, Sood A, Madi R, Klaassen Z, Badani K et al. (2016) Zero-fragment Nephrolithotomy: A Multi-center Evaluation of Robotic Pyelolithotomy and Nephrolithotomy for Treating Renal Stones. Euro urol pii: S0302-2838(16)30724-2.

12. Kijvikai K (2011) The role of laparoscopic surgery for renal calculi management. Ther Adv Urol 3(1): 13-18.

13. Albuquerque Lde A, Camilo-Silva DG, Fiedler G, Corguinha GB, Paiva MM, et al. (2015) Review on renal recovery after anatrophic nephrolithotomy: Are we really healing our patients? World J Nephrol 4(1): 105-110.

14. Andrei Nadu, Oscar Schatloff, Roy Morag, Ramon J, Winkler H (2009) Laparoscopic Surgery for Renal Stones: Is it Indicated in the Modern Endourology Era? Int Braz J Urol 35(1): 9-18.

15. Melissourgos N, Davilas E, Fragoulis A (2002) Modified Anatrophic Nephrolithotomy for Complete Staghorn Calculus Disease - Does it Still Have a Place? Scand J Urol Nephrol 36(6): 426-430.

16. Simforoosh N, Aminsharifi A, Tabibi A, Noor-Alizadeh A, Zand S, et al. (2008) Laparoscopic anatrophic nephrolithotomy for managing large staghorn calculi. BJU Int 101(10): 1293-1296.

17.Zhou L, Xuan Q, Wu B, Xiao J, Dong X, et al. (2011) Retroperitoneal laparoscopic anatrophic nephrolithotomy for large staghorn calculi. Int J Urol 18(2): 126-129.

18. Giedelman C, Arriaga J, Carmona O, de Andrade R, Banda E, et al. (2012) Laparoscopic anatrophic nephrolithotomy: Developments of the technique in the era of minimally invasive surgery. J Endourol 26(5): 444-450. 
(C) Therk is licensed under Creative

(CC) BY Commons Attribution 4.0 License

\section{Your next submission with Juniper Publishers} will reach you the below assets

- Quality Editorial service

- Swift Peer Review

- Reprints availability

- E-prints Service

- Manuscript Podcast for convenient understanding

- Global attainment for your research

- Manuscript accessibility in different formats

( Pdf, E-pub, Full Text, Audio)

- Unceasing customer service

Track the below URL for one-step submission https://juniperpublishers.com/online-submission.php 